\title{
HUBUNGAN ANTARA PENGETAHUAN LINGKUNGAN, STATUS SOSIAL EKONOMI DENGAN PERILAKU HIDUP SEHAT
}

\author{
Sri Yamti Runtuni \\ Dosen Jurusan Geografi FIS UNJ \\ E-mail: sriyamti@unj.com
}

\begin{abstract}
The research is in purpose to obtain the description and information about environmental science, social-economy status with heathy attitude lifestyle. This research uses two independent variables that is environmental science and social-economy status, and one dependent variables that is heathy attitude lifestyle. Methode's application is survey methode. This research has been held in Subdistrict Pasar Rebo East Jakarta on Novembre until Decembre 2011. The research's sample is PKK (Housewifes Community) members team of working group (POKJA) as much as 70 persons. Analisys results showed, first: there is a positive relation between environmental science $\left(X_{1}\right)$ with healthy attitude lifestyle (Y). As being indicated by correlation coefficient (r) 0,558 and simple linear regression $\dot{Y}=88,45+1,49 X$ and determination coefficient $\left(r^{2}\right)$ 0,3114, second: there is a positive relation between social-economy status $\left(X_{2}\right)$ with heathy attitude lifestyle $(Y)$, As being indicated by correlation coefficient (r) 3,46 with simple linear regression $Y=93,76+3,46 X_{2}$; Third: there is a positive relation between environmental science and social-economy together with heathy attitude lifestyle, as being indicated by double correlation coefficient $(R) 0,450$, with determination coefficient $R^{2} 0,450$ and with double linear regression $Y=82,38+0,98 X_{2}+2,47 X_{2}$. This research's results put up implication that environmental science and social-economy status are two variables which gave a contribution to PKK (Housewifes Community) member's heathy attitude lifestyle in subditrict Pasar Rebo East Jakarta.
\end{abstract}

Kata Kunci : Pengetahuan, Sosial, Ekonomi.

\section{PENDAHULUAN}

Pemberdayaan dan Kesejahteraan

Keluarga (PKK) Kecamatan Pasar Rebo, Jakarta Timur merupakan pemberdayaan yang menjalankan Visi dan Misi sesuai dengan pedoman gerakan PKK. Tujuan intinya yaitu terwujudnya keluarga yang sejahtera, maju, dan mandiri melalui pemberdayaan kesejahteraan keluarga. Adapun jumlah kader PKK dengan rincian ; Tim Penggerak PKK berjumlah 158 orang, Tim PKK RW berjumlah 159 orang. Pelaksanaan PKK berjalan sesuai dengan hasil Rakermas VII PKK tahun 2010 didapatkan 3 program pokok, kepribadian PKK tidak boleh meninggalkan kodrat fungsionalnya untuk senantiasa memelihara lingkungan yang bersih dan nyaman, meningkatkan kemampuan secara profesionalnya di bidang kesehatan, mutu pendidikan dan keterampilan bagi masyarakat dan tumbuh kembang anak serta peningkatan pendapatan keluarga dengan kegiatan ekonomi produktif. Contoh kegiatannya antara lain arisan, kursus-kursus, penyuluhan kesehatan ibu anak dan keluarga, penyuluhan lingkungan untuk masing-masing RW mengenai lingkungan dalam menanggulangi banjir, kebersihannya agar penyakit demam berdarah tidak menyerang RW, pembuatan resapan air hujan di tempat tinggalnya, pekarangan rumah perlu diberi tanaman, pelatihan membuat pupuk kompos, penyuluhan daur ulang dan cara membuang sampah organik dan anorganik. Dengan berbagai kegiatan tersebut agar di era modern dan era global bisa menghadapi hidup sehat sesuai dengan pengetahuan lingkungan secara individu ataupun kelompok berdasarkan status sosial ekonomi Ibu-lbu PKK.

PKK Kecamatan Pasar Rebo mempunyai struktur seperti PKK di seluruh Indonesia yaitu di setiap kelurahan mempunyai Tim Penggerak Program Kelompok Kerja Satu (I) yang terdiri dari 3 orang, Program Kelompok Kerja Dua (II) yang terdiri dari 3 orang, Program Kelompok Kerja Tiga (III) yang terdiri dari 3 orang, Program Kelompok Kerja Empat (IV) 
yang terdiri dari 3 orang dan Program POKSUS UP2K yang terdiri dari 2 orang. Jadi jumlah tim penggerak program kerja setiap kelurahan berjumlah 14 orang. Sehingga, jumlah tim penggerak PKK Kecamatan Pasar Rebo sebanyak 5 kelurahan dikali 14 orang yaitu 70 orang.

Bertolak dari uraian diatas maka perilaku tim penggerak kelompok kerja hidup sehat dari Ibu Ibu PKK Kecamatan Pasar Rebo Jakarta Timur dihubungkan dengan pengetahuan lingkungan serta status sosial ekonomi dengan semakin berkembangnya ilmu pengetahuan dan teknologi diberbagai bidang pembangunan nasional yang berwawasan sumberdaya manusia mendapat prioritas, peneliti tertarik untuk mengelaborasi hubungan antara pengetahuan lingkungan, status sosial ekonomi dengan perilaku hidup sehat.

\section{METODOLOGI PENELITIAN}

Penelitian ini dilaksanakan di Kecamatan Pasar Rebo Jakarta Timur, dengan subyek penelitian adalah pengurus PKK di Kecamatan Pasar Rebo. Penelitian ini dilaksanakan pada Bulan November-Desember 2011, dan melalui beberapa tahap antara lain studi pendahuluan, ujicoba, pengumpulan data, serta pengolahan analisa data. Tujuan untuk penelitian ini yaitu untuk mengetahui hubungan antara : (1) Pengetahuan lingkungan dengan perilaku hidup sehat (2) Status sosial ekonomi dengan perilaku hidup sehat (3) Pengetahuan lingkungan, status sosial ekonomi dengan perilaku hidup sehat. Penelitian ini menggunakan metode survey. Hubungan antara variabel tersebut dapat dijelaskan melalui gambar sebagai berikut:

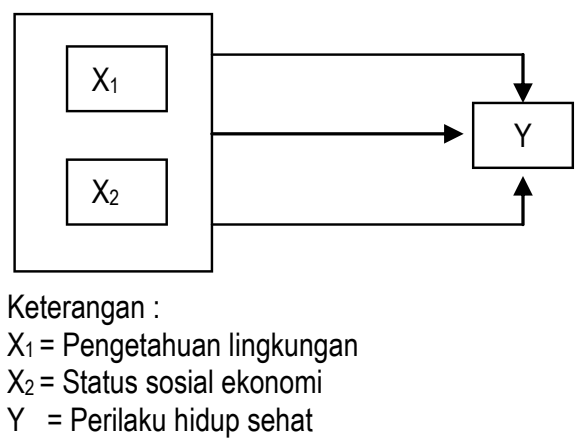

Dalam penelitian ini yang menjadi populasi sasaran (target) adalah seluruh Ibu-ibu Tim Penggerak PKK di Kecamatan Pasar Rebo Jakarta sejumlah 158 orang. Sedangkan populasi terjangkau adalah lbu-ibu PKK tim kelompok kerja (pokja) sebanyak 70 orang, yang berasal dari 5 kelurahan, yang masingmasing terdiri dari 14 orang.

\section{HASIL PENELITIAN}

\section{Pengujian Persyaratan Analisis}

Ada tiga syarat yang harus dipenuhi sebelum melakukan analisis regresi, baik regresi linier sederhana maupun regresi ganda, yaitu (1) normalitas galat taksiran; (2) homogenitas varians kelompok-kelompok skor $Y$ yang dikelompokkan berdasarkan kesamaan data variabel $X$; (3) linieritas regresi. Dari ketiga persyaratan tersebut ada dua persyaratan yang disajikan pengujiannya pada bagian ini, yaitu uji normalitas dan uji homogenitas varians kelompok-kelompok skor $Y$ berdasarkan kesamaan data $X$, sedangkan uji linieritas regresi akan diuji dalam pengujian hipotesis penelitian.

Uji Normalitas
Pengujian persyaratan normalitas
dilakukan dengan menggunakan teknik uji
Liliefors. Kriteria pengujian tolak $\mathrm{H}_{0}$
menyatakan bahwa skor berdistribusi normal
adalah, jika Lhitung lebih kecil dibandingkan
dengan Ltabel maka $\mathrm{H}_{0}$ tidak dapat ditolak,
dalam hal lainnya $\mathrm{H}_{0}$ tidak dapat diterima. Dari
hasil penelitian dapat diketahui bahwa IF(zi) -
$\mathrm{S}(z i) I$ yang disimpulkan dengan Lhitung untuk
kedua galat taksiran lebih kecil dari nilai $\mathrm{L}_{\text {tabel, }}$
batas penolakan $\mathrm{H}_{0}$ yang tertera pada tabel
Liliefors.
Berdasarkan hal tersebut, maka dapat
disimpulkan bahwa semua hipotesis nol ( $\left.\mathrm{H}_{0}\right)$
yang berbunyi sampel berasal dari populasi
berdistribusi normal tidak dapat ditolak, dengan
kata lain bahwa semua sampel yang terpilih
berasal dari populasi yang berdistribusi normal.

Berdasarkan hal tersebut, maka dapat disimpulkan bahwa semua hipotesis nol $\left(\mathrm{H}_{0}\right)$ yang berbunyi sampel berasal dari populasi berdistribusi normal tidak dapat ditolak, dengan kata lain bahwa semua sampel yang terpilih 
Tabel 1. Hasil Pengujian Normalitas Galat Taksiran

\begin{tabular}{llccccc}
\hline & Gakat Taksiran Regresi & \multirow{N}{*}{$\mathrm{N}$} & Lhitung & $\mathrm{a}=5 \%$ & $\mathrm{~L}$ Label & \multirow{2}{*}{ Ket } \\
\hline 1 & $\mathrm{Y}$ atas $\mathrm{X}_{1}$ & 70 & 0,0933 & 0,106 & 0,121 & Normal \\
2 & $\mathrm{Y}$ atas $\mathrm{X}_{2}$ & 70 & 0,0551 & 0,106 & 0,121 & Normal \\
\hline
\end{tabular}

Sumber: Penelitian 2011.

Berdasarkan harga-harga $L_{\text {hitung }}$ dan $L_{\text {tabel }}$ di atas dapat disimpulkan pasangan semua data dari variabel baik perilaku hidup sehat $(Y)$ atas pengetahuan lingkungan $\left(X_{1}\right)$, dan perilaku hidup sehat $(Y)$ atas status sosial ekonomi $\left(X_{2}\right)$ berasal dari sampel yang berdistribusi normal.

\section{Uji Homogenitas}

Uji homogenitas varians dimaksudkan untuk menguji homogenitas varians antara kelompok-kelompok skor variabel terikat $(Y)$ yang dikelompokkan berdasarkan kesamaan nilai variabel bebas $(X)$. Pengujian homogenitas varians dilakukan dengan uji Bartlett.

Hasil perhitungan untuk pengujian homogenitas varians instrumen perilaku hidup sehat atas instrumen pengetahuan lingkungan diperoleh $\chi^{2}$ hitung sebesar 6,561 . Nilai $\chi^{2}$ tabel dengan dk 11 pada $a=0,05$ sebesar 19,675. Oleh karena $\chi^{2}$ hitung $<\chi^{2}$ tabel, maka $\mathrm{H}_{0}$ diterima. Hal ini berarti varians kelompok-kelompok instrumen perilaku hidup sehat atas instrumen pengetahuan lingkungan adalah homogen.

Hasil perhitungan untuk pengujian homogenitas varians instrumen perilaku hidup sehat atas instrumen status sosial ekonomi diperoleh $\chi^{2}$ hitung sebesar 6,613 . Nilai $\chi^{2}$ tabel dengan dk 6 pada $a=0,05$ sebesar 12,592. Oleh karena $\chi^{2}$ hitung $<\chi^{2}$ tabel, maka $\mathrm{H}_{0}$ diterima. Hal ini berarti varians kelompok-kelompok instrumen perilaku hidup sehat atas instrumen status sosial ekonomi adalah homogen. Keseluruhan hasil uji homogenitas varians dirangkum pada tabel berikut ini.

Tabel 2. Hasil Pengujian Homogenitas Varians

\begin{tabular}{ccccccc}
\hline \multirow{2}{*}{ No } & Variabel & Dk & $\chi^{2}$ itung & \multicolumn{2}{c}{$\chi^{2}$ tabel } & \multirow{2}{*}{ Ket } \\
& & 11 & 6,561 & 19,675 & 24,725 & Homogen \\
\hline 1 & $Y$ atas $X_{1}$ & 11 & & & \\
2 & $Y$ atas $X_{2}$ & 6 & 6,163 & 12,592 & 16,812 & Homogen \\
\hline \multicolumn{2}{l}{ Sumber: Penelitian 2011. }
\end{tabular}

Berdasarkan harga-harga $\chi^{2}$ hitung dan $\chi^{2}$ tabel di atas dapat disimpulkan pasangan semua data dari variabel baik perilaku hidup sehat $(Y)$ atas pengetahuan lingkungan $\left(X_{1}\right)$, dan perilaku hidup sehat $(Y)$ atas status sosial ekonomi $\left(X_{2}\right)$ berasal dari sampel yang homogen.

Beberapa pembahasan dan interpretasi hasil penelitian di atas secara lebih mendalam dikemukakan pada uraian di bawah ini.

Pertama, hasil pengujian hipotesis pertama dapat disimpulkan bahwa terdapat hubungan positif antara pengetahuan lingkungan dengan perilaku hidup sehat. Kesimpulan tersebut menunjukkan bahwa semakin tinggi pengetahuan lingkungan, maka akan semakin tinggi pula perilaku hidup sehat.

Kuadrat koefisien korelasi antara kedua variabel $\left(r^{2} y 1\right)$ sebesar 0,3114 dapat diinterpretasikan bahwa bila tidak dilakukan kontrol terhadap variabel lain, maka $31 \%$ proporsi variansi perilaku hidup sehat dapat dijelaskan oleh tingkat pengetahuan lingkungan.

Sedangkan dari bentuk hubungan antara pengetahuan lingkungan $\left(X_{1}\right)$ dengan perilaku hidup sehat $(Y)$ ditunjukkan oleh persamaan garis regresi sederhana $\hat{Y}=88,45+1,49 X_{1}$. Persamaan garis regresi tersebut menunjukkan kebermaknaannya yang berarti pada taraf signifikansi $5 \%$. Persamaan garis tersebut dapat diinterpretasikan bahwa perubahan satu unit skor perilaku hidup sehat akan diikuti oleh perubahan skor pengetahuan lingkungan sebesar 1,49 unit pada arah yang sama dengan konstanta (intercept) sebesar 88,45.

Korelasi antara pengetahuan lingkungan dengan perilaku hidup sehat menunjukkan kebermaknannya, baik melalui korelasi product moment maupun korelasi parsial. Hasil analisis 
ini memberikan petunjuk bahwa pengetahuan lingkungan merupakan salah satu faktor utama yang berkonstribusi terhadap perilaku hidup sehat. Dari hasil itu pula dapat diinterpretasikan bahwa peningkatan pengetahuan lingkungan akan memberikan konstribusi yang berarti terhadap perilaku hidup sehat.

Kedua, dari hasil pengujian hipotesis kedua dapat disimpulkan bahwa terdapat hubungan antara status sosial ekonomi dengan perilaku hidup sehat. Kesimpulan tersebut menunjukkan bahwa semakin tinggi status sosial ekonomi, maka akan semakin tinggi pula perilaku hidup sehat.

Kuadrat koefisien korelasi antara kedua variabel $\left(r^{2}{ }^{2}\right)$ sebesar 0,3505 dapat diinterpretasikan bahwa bila tidak dilakukan kontrol terhadap variabel lain, maka 35\% proporsi variansi perilaku hidup sehat dapat dijelaskan oleh tingkat status sosial ekonomi.

Sedangkan dari bentuk hubungan antara status sosial ekonomi $\left(X_{2}\right)$ dengan perilaku hidup sehat $(Y)$ ditunjukkan oleh persamaan garis regresi sederhana $\hat{Y}=93,76+3,46 X_{2}$. Persamaan garis regresi menunjukkan kebermaknaan yang berarti pada taraf signifikansi $5 \%$. Persamaan garis regresi tersebut dapat diinterpretasikan bahwa perubahan satu unit skor perilaku hidup sehat akan diikuti oleh perubahan skor status sosial ekonomi sebesar 3,46 unit pada arah yang sama dengan konstanta (intercept) sebesar 93,76 .

Korelasi antara status sosial ekonomi dengan perilaku hidup sehat menunjukkan kebermaknannya, baik melalui korelasi product moment maupun korelasi parsial. Hasil analisis ini memberikan petunjuk bahwa status sosial ekonomi merupakan salah satu faktor utama yang berkonstribusi terhadap perilaku hidup sehat. Dari hasil itu pula dapat diinterpretasikan bahwa peningkatan status sosial ekonomi akan memberikan konstribusi yang berarti terhadap perilaku hidup sehat.

Ketiga, dari hasil pengujian hipotesis ketiga dapat disimpulkan bahwa pengetahuan lingkungan dan status sosial ekonomi secara bersama-sama mempunyai hubungan positif dengan perilaku hidup sehat. Koefisien korelasi ganda antara kedua variabel bebas dengan variabel terikat $R_{y 12}$ sebesar 0,671. Dari koefisien korelasi tersebut, dapat dihitung koefisien determinasi $\left(R^{2} y 12\right)$ sebesar 0,4506 berarti bahwa $45 \%$ proporsi varaians perilaku hidup sehat dapat dijelaskan secara bersamasama oleh pengetahuan lingkungan serta status sosial ekonomi.

\section{KESIMPULAN}

Pertama, pengetahuan lingkungan $\left(X_{1}\right)$ mempunyai hubungan positif dengan perilaku hidup sehat (Y). Kekuatan hubungan itu ditunjukkan oleh koefisien korelasi (r) sebesar 0,558 dan bentuk hubungan dengan regresi linear sederhana $\dot{Y}=88,45+1,49 X$ koefisien determinasi $\left(r^{2}\right)$ sebesar 0,3114 , ini menunjukkan bahwa variasi yang terjadi pada perilaku hidup sehat sebesar $31 \%$ dapat dijelaskan oleh pengetahuan sosial melalui persamaan regresi linier sederhana $\dot{Y}=88,45+$ $1,49 X_{1}$ yang telah diuji keberartiannya. Karena itu hasil penelitian ini menyimpulkan bahwa terdapat hubungan positif antara lingkungan hidup dengan perilaku hidup sehat, artinya makin tinggi status pengetahuan lingkungan semakin tinggi perilaku atau lebih positif dalam memberi kontribusi dalam hidup sehat ibu-ibu PKK Pasar Rebo Jakarta Timur.

Kedua; selain pengetahuan lingkungan, faktor lain yang juga berhubungan dengan perilaku hidup sehat, status sosial ekonomi $\left(X_{2}\right.$ ) mempunyai hubungan positif dengan perilaku hidup sehat $(Y)$, kekuatan hubungan antara status sosial ekonomi dengan perilaku hidup sehat ditunjukkan oleh koefisien korelasi ( $r$ ) sebesar 3,46 dan bentuk hubungan dengan regresi linier sederhana $\dot{Y}=93,76+3,46 X_{2}$ dan juga telah di uji keberartiannya. Hal ini menunjukkan hasil penelitian ini dapat disimpulkan bahwa ; terdapat hubungan positif antara status sosial ekonomi dengan perilaku hidup sehat, artinya semakin tinggi status sosial ekonomi seseorang maka diharapkan semakin tinggi perilaku hidup sehat.

Ketiga ; Disamping itu hasil penelitian ini juga menunjukkan bahwa pengetahuan lingkungan dan status sosial ekonomi $\left(X_{2}\right)$ secara bersama-sama memiliki hubungan positif dengan perilaku hidup sehat $(Y)$, kekuatan hubungan tersebut ditunjukkan oleh 
koefisien korelasi ganda (R) sebesar 0,45, dengan koefisien determinasi $R^{2}$ sebesar 0,45 ini berarti bahwa variasi yang terjadi pada pengetahuan lingkungan sebesar $45 \%$ dapat dijelaskan secara bersama-sama oleh status sosial ekoomi dengan perilaku hidup sehat melalui persamaan regresi linier ganda $\dot{Y}=$ $82,38+0,98 X_{2}+2,47 X_{2}$ yang telah teruji keberartiannya. Dengan demikian dapat dikatakan bahwa terdapat hubungan positif antara pengetahuan lingkungan, status sosial ekonomi dengan perilaku hidup sehat. Artinya perilaku hidup sehat dapat ditingkatkan apabila pengetahuan lingkungan dan sosial ekonomi semakin tinggi.

Dari hasil-hasil penelitian ini menunjukkan bahwa masih terdapar faktorfaktor lain mempengaruhi perilaku hidup sehat. $\mathrm{Hal}$ ini dapat dilihat dari variasi yang terjadi pada perilaku hidup sehat sebesar $45 \%$ yang dapat dijelaskan secara bersama-sama oleh variabel pengetahuan lingkungan, status sosial ekonomi dan masih lebih banyak lagi yang dapat dijelaskan oleh variabel-variabel lain.

\section{DAFTAR PUSTAKA}

Azwar Saifuddin, MA. Reliabilitas dan Validitas. Yogyakarta : Pustaka Pelajar. 2004.

Arikunto. Dasar-Dasar Evaluasi Pendidikan. Bandung: Remaja Rosda Karya. 1992

Benyamin, Bloom S. (ed), Taxonomy of Educational Objectives: Book Cognitive Domain. London:, Longman Group Limeted. 1979.

Bintarto, R, Suatu Pengantar Geografi Desa. Jogyakarta: UP Spring.1977.

Dali s. Naga, Pengantar Teori Skor Pada Pengukuran Pendidikan. Jakarta: Besbats. 1992.

Darwin, Sudarwan, IImu-IImu Perilaku. Jakarta: Bumi Aksara. 1997
Donald Ary, L. Ch. Yacobs and Razavich, Introduction in Research in Education Sydney: Holt Rinehart and Winston. 1979

Elzey, Freeman, Interductory Statistics A Microcomputer Approach: Monterey, California, USA, 1985

Harvy, Nassir, Masalah Kota Jakarta: Pusat Sumber Daya Manusia Jakarta. 1979

Herlianto, Urbanisasi dan Pembangunan Kota: Bandung: Alumni. 1994

Juli, Slamet. S, Kesehatan Lingkungan. Jogyakarta: Gajah Mada University Press. 1994

Kusnopuranto, Haryono, Kesehatan Lingkungan. Jakarta: Fakultas Kesehatan Masyarakat UI. 1986

L.Thomas, Good Al Educational Psychology. London: Long Man. 1990

Neo Laka, Amos, Kesadaran Lingkungan. Jakarta: Rineka Cipta. 2008

Notoadmodjo Sukijo, Promosi Kesehatan dan Perilaku. Jakarta: Rineka Cipta. 2007

Soekamto, Soeyono, Sosiologi. Jakarta: PT. Raja Grafindo Persada. 2006

Sudarwan,Darwin, IImu-IImu Perilaku. Jakarta: Bumi Aksara.1997

Sudjana, Nana, Teori-teori Belajar untuk Pengajaran. Jakarta: Universitas Ekonomi Indonesia. 1990

Sumaatmadja, Nursid, Studi Geografi Suatu Pendekatan dan Analisa Keruangan. Bandung. 1988

Stanley Julia C and Kenneth, Phipkirs: Educational and Psychological Measurement and Evaluation: New Yersey, Praktis Hall

Sumarwoto, Otto, Ekologi Lingkungan Hidup dan Pembangunan. Jakarta: Djambatan. 2004

Suriasumantri, Yuyun S, IImu dalam Prespektif. Jakarta: Yayasan Obor Indonesia. 2001. 